Makale türü / Article type: Araştırma / Research

\title{
Üniversite Öğrencilerinin Mobil Oyun Profili ve Oynama Alışkanlıkları \\ ***
}

\section{University Students' Mobile Game Profiles and Playing Habits}

\author{
Erkan Yavuz \\ Kastamonu Üniversitesi, Sosyal Bilimler Enstitüsü, Yük. Lisans Öğr. \\ erkannyavuz@gmail.com; (ORCID: 0000-0002-4143-1056) \\ Dr. Öğr. Üyesi Elif Tarlakazan \\ Kastamonu Üniversitesi, Güzel Sanatlar ve Tasarım Fakültesi, \\ etarlakazan@kastamonu.edu.tr; (ORCID: 0000-0001-5381-9755)
}

\section{Özet}

Günümüzde internet ve bilgisayar kullanımı, mobil teknoloji ürünlerinin gelişmesiyle birlikte farklı bir boyut kazanmış, bu ürünlerin kolay ulaşılabilir ve taşınabilir olması yaşamın vazgeçilmez unsurları arasında yerini almasını sağlamıștır. Araştırmada dijital oyun kavramı ve türleri, üniversite öğrencilerinin mobil oyun alışkanlıkları ve tercihleri incelenmiştir. $\mathrm{Bu}$ bağlamda araştırmanın temel amacı üniversite öğrencilerinin mobil oyunlara bakışı ve oynama alışkanlıklarını belirlemektir. Araştırmada Kastamonu Üniversitesi Güzel Sanatlar ve Tasarım Fakültesi öğrencileri örneklem grubu olarak kullanılmıştır. Araştırma kapsamında öğrencilere yapılandırılmış anket formu uygulanmıştır. Araştırma sonucunda öğrencilerin mobil cihazlarını en çok sosyal medya ve internet için kullandıkları, mobil oyun oynayanların genellikle aksiyon/macera oyunlarını tercih ettikleri, yeni çıkan mobil oyunlardan en çok arkadaşları tarafından haberdar oldukları, oyun oynama amaçlarının zevk eğlence olduğu, mobil oyunların yabancı dil öğrenimine kısmen katkı sağladığı ve boş zamanlarını genellikle oyun oynayarak geçirdikleri bilgilerine ulaşılmıştır.

Anahtar Kelimeler: Mobil Oyun, Dijital Oyun, Oyun Tercihleri, Oyun Türü ve Alışkanlıkları.

\section{JEL Sınıflandırması: Q55}

\begin{abstract}
Today, the use of Internet and computer has gained a different dimension with the development of mobile technology products, and the easy accessibility and mobility of these products has enabled them to take place among the indispensable elements of
\end{abstract}


life. In this study, the concept and types of digital games, mobile game habits and preferences of university students were studied. In this context, the main purpose of the research is to determine the way university students look at mobile games and play habits. In this study, the students of the Faculty of Fine Arts and design of Kastamonu University were used as sample groups. Within the scope of the research, the questionnaire was applied to the students. The results of the research revealed that the students most used mobile devices for social media and Internet, mobile gamers mostly prefer action/adventure games, they are most aware of emerging mobile games by their friends, the enjoyment of playing games is entertainment, mobile games contribute partly to foreign language learning and spend their spare time playing games.

Key Words: Mobile Game, Digital Game, Game Preferences, Game Type and Habits.

\section{JEL Classification: Q55}

\section{GíRIŞ}

Bilgisayarlar üzerinde yapılan işlemlerin birçoğu akıllı telefon, tablet gibi mobil cihazlar tarafından gerçekleştirilmekte olup bilgisayara duyulan ihtiyaç her geçen gün azalmaktadır. Özellikle günlük internet kullanım süresinin günlük bilgisayar kullanım süresinden daha fazla olması, internet kullanım aracı olma özelliğinin bilgisayarlardan mobil cihazlara geçmeye başladığının bir göstergesidir (Çelik \& Akadal, 2014).

Mobil teknolojilerindeki hızlı gelişmeler sonucunda geleneksel bilgisayar uygulamaları yerini mobil uygulamalara bırakmaya başlamaktadır. Bu uygulamalar mobil platformlar sayesinde her zaman erişilip kullanılabilir niteliğe bürünmektedir (Özkoçak, 2016). Özellikle bilgisayarları dijital oyun aracı olarak kullanan bireyler için mobil cihazlar günümüzde taşınabilir ve her ortamda oynanabilir olmasından dolayı daha çok tercih edilmektedir.

Mobil cihaz uygulamalarıyla birlikte sosyal ağ siteleri, çevrimiçi oynanan oyunlar, video paylaşım siteleri ve mobil uygulamalar yeni dönem gençlik kültürünün demirbaşları halini almaktadır. Gençler kendilerini ifade etmek ve benliklerini ortaya koymak için bu araçlardan yararlanmaktadır (Bal, 
2013). Özellikle gençler başta olmak üzere mobil cihazları dijital oyun aracı olarak kullanan kişilerin sayısı bir hayli fazladır.

Gelişen teknoloji ile oyun kavramı; bilgisayar oyunları, video oyunları ve taşınabilir cihazlarla oynanan mobil oyunlar olarak karşımıza çıkmaktadır. "Video oyunları", "bilgisayar oyunları" ve "mobil oyunları" terimleri birbirlerinin yerine dönüşümlü olarak kullanılmakta olup bu ortaklardan yola çıkılarak bu çalışmada video, bilgisayar ve mobil oyunlar "dijital oyunlar" olarak adlandırılmaktadır (Pala \& Erdem, 2011).

Dijital oyun; bilgisayar tabanlı, metin ya da görsellik üzerine inşa edilmiş, akıllı telefon, bilgisayar ya da tablet gibi elektronik platformlar üzerinde bir veya birden fazla kişinin fiziksel ya da çevrimiçi ağ üzerinden birlikte kullanabildiği bir eğlence ve boş zaman aktivitesi olan yazılım olarak tanımlanmaktadır (Frasca, 2001).

Dijital oyunlar yeni medya kültürünün önemli bir parçası haline gelmektedir. Aynı zamanda aktif katılımlı olduklarından dolayı sosyal ağlar ve sanal gerçeklik platformları ile de yeni bir medya kullanımına işaret etmektedir. Dijital oyunlar platformlarına dünyanın her yerinden kullanıcılar eş zamanlı olarak katılabilmekte, kültürel bağlamlar ile kimlikler ortaya koyabilmekte, iş birliğine dayalı sosyal etkileşim gerçekleştirebilmektedirler. Dijital oyunların gerek online gerekse sanal gerçeklik odaklı yapıları kullanıcılara farklı platformlar sundukları söylenebilir.

Dijital oyunların eğlenceli, kişisel tercihlerin öne çıktığı, aktif katılımı sağlayan dinamik yapısı hedef kitle için tercih nedenleri arasındadır. Tanıtım, eğlence, eğitim, yayıncılık gibi birçok konu alanına dayalı dijital oyun platformları vardır (Erişti, 2016).

Dijital oyunlar farklı ölçütlere göre sınıflandırabilmektedir. Örneğin; oyun oynama platformlarına göre bilgisayar oyunları, konsol oyunları, mobil oyunlar gibi sınıflara ayırmak mümkündür. Oyuncu sayılarına göre; tek kişilik, iki kişilik, çok kişili oyunlar ve çevrimiçi oyunlar olarak ayırabilir. Oyuncunun oyuna bakış açısına göre First Person Shooter (birinci kişi gözünden), Third Person Shooter (üçüncü kişi gözünden) ya da God (tanrı) 
gözünden olarak sinıflandırılabilmektedir. Burada ise Rapeepisarn ve arkadaşlarının 2008 yılında yaptıkları çalışmaya göre yedi farklı dijital oyun türü aktarılacaktır. Bunlar: aksiyon/macera oyunları, dövüş oyunları, spor oyunları, simülasyon oyunları, strateji oyunları, eğitici oyunlar, rol yapma oyunlarıdır (Kaya, 2013).

Aksiyon/Macera Oyunlart: Bu tür oyunlarda oyuncunun haz aldığı şey oyun içerisinde ona sunulan bulmacaların çözümüdür. Aksiyon/macera oyunlarında düzey atlama ya da geliştirme söz konusu değildir. Bu rağmen ideal karakter, oyun süresi boyunca dönüşüm, değişim geçirir (Binark \& Bayraktutan Sütçü, 2008). Örnek: Counter Terrorist- Swat, Mobile Legends, N.O.V.A Legacy, Criminal Case, Minecraft, Darkland vb.

Dövüş Oyunları: Bu tür oyunların amacı belirli bir sürede farklı özellikleri olan karakterleri kullanarak rakibi yenmektir. Dövüş oyunlarında genellikle seviye atlama veya karakter oluşturma seçenekleri yoktur. Oyun ilerledikçe daha güçlü karakterlerle mücadele edilir (Kaya, 2013). Örnek: Shadow Fight, Fists For Fighting, Fighting Tiger- Liberal, Kung Fu Do Fighting vb.

Spor Oyunları: Bu tür oyunlar fiziksel hareketlerin ve tekniklerin önemli olduğu oyunlardır (Yalçın Irmak \& Erdoğan , 2016). 8 Ball Pool, Fifa Mobile Futbol, Top Eleven Futbol Menajeri, Dream League, Futbol Manager Mobile 2017 vb.

Simülasyon Oyunlart: Bir eylemle ilgili pratik yapmak, bir aracı kullanmak ya da dünya kurmakla ilgili genellikle hiç bitmeyen şekilde tasarlanan oyunlardır (Yalçın Irmak \& Erdoğan , 2016). Bu tür oyunlarda belirgin bir hedef yoktur. Örnek: Dragon City, Vegas Crime, Farming Simulator 16, Bridge Constructor, Bus Simulator PRO 2017 vb.

Strateji Oyunları: Oyuncuların sorunların üstesinden gelmesi, taktiksel karar alması gerekli olan oyunlardır. Kendi içerisinde savaş, gerçek zamanlı strateji, ekonomik ya da politik olmak üzere üçe ayrılır (Kaya, 2013). King of Avalon: Dragon Warfare, Mobile Legends, Boom Beach, Demonrock: War of Ages, Grand Battle gibi oyunlar bu oyun türüne örnek verilebilir. Clash 
Royale, Clash of Kings, Clash of Clans, Last Empire-War Z, Mobile Strike, Bloons TD $5 \mathrm{vb}$.

Ĕ̈itici Oyunlar: Oynayanları sınırlandırmadan yaratıcı ve keşfedici öğrenmeye yönlendirerek problem çözme yeteneklerinin gelişmesini sağlayan oyunlardır (Aykutlu \& Şen, 2004). Bu uygulamalar hataları düzeltme, eğlenceli şekilde öğrenme, keşfederek öğrenme, yaparak öğrenme gibi yöntemlerle öğrenmeyi sağlar. Fun with Activities, Funny Food2, Bilgi Yarışması, My Town: Preschool, Learn Japanese wit Tako, Fransızca Öğreniyorum- Lanquick, TRT Bulmaca Kulesi, Matematik Oyunu vb.

Rol Yapma Oyunlart: Oyuncu, oyundaki karakterlerin herhangi birinin rolünü üstlenerek oyun dahil olup belirli bir senaryoyu ya da kendileri tarafinda yaratılan bir hikayeyi oynar. Bu oyunda amacı seçilen karakterlere rol yaparak bürünmek ve kendisine verilen görevleri yapıp karakterleri geliştirmeye çalışmaktır (Karahisar, 2013). Arcane Legends, Blood Brothers, Dungeon Quest, Camelot'un Kahramanları, Infinity Dungeon Evolution!, The Banner Saga, Chains of Darkness: Guilds CCG vb.

Mobil oyunla ilgili literatür incelendiğinde oyun kavramına ilişkin çeşitli tanımlamalara ve oyunun çocuğun hakkı olduğuna, oyun algısına, mobil oyun tercihinde etkili olan faktörlere, dijital oyunlardaki şiddet faktörleri ile ilgili konulara yer verildiği görülmektedir (Aydoğdu Karaaslan, 2015; Altuntaş \& Karaarslan, 2017; Koçyiğit ve Baydilek, 2015; Küçükali, 2015). Bu çalışmada ise mobil oyunun üniversite öğrencileri tarafından nasıl algılandığı, oyunla ilgili tercihlerinde nelere önem verdikleri ve alışkanlıkları belirlenmeye çalışılmıştır. Bunun yanı sıra, öğrencilerin cinsiyetleriyle mobil oyun oynama tercihleri arasında bir ilişki olup olmadığını ortaya çıkarmak da hedeflenmiştir.

$\mathrm{Bu}$ doğrultuda araştırmanın amacı, üniversite öğrencilerinin mobil oyunlara bakışı ve oynama alışkanlıklarını belirlemektir. Araştırmada tarama modeli kullanılmıştır. Ulaşılan yerli ve yabancı makale, kitap, dergi, rapor, internet aracılığıyla elde edilen çeşitli yazı ve dokümanlar belirlenen amaç doğrultusunda incelenmiştir. 


\section{YÖNTEM}

$\mathrm{Bu}$ araştırma, "Üniversite Öğrencilerinin Mobil Oyun Profili ve Oynama Alışkanlıkları"nı sorgulayan yapılandırılmış çoktan seçmeli soru formu ile elde edilen verilerin nicel veri analizine dayalı bir çalışmasıdır. Araştırmada veri toplama aracı olarak kullanılan anket araştırmacılar tarafından hazırlanmıştır. Araştırma grubunu 2016-2017 eğitim-öğretim yılında Kastamonu Üniversitesi Güzel Sanatlar ve Tasarım Fakültesi'nde eğitim gören 91 öğrenci oluşturmaktadır. Grafik Tasarım, Resim, Geleneksel Türk El Sanatları, Seramik olmak üzere toplam dört farklı programdan öğrenciler araştırmaya katılmıştır. Anketin uygulanmasını araştırmacılar gerçekleştirmiştir. Anket formunda çoktan seçmeli ve açık uçlu sorulara yer verilmiştir. Anket, son şeklini alıncaya kadar çeşitli pilot testlerle iyileştirilmiştir. Araştırmacı, dersin öğretmeni ile birlikte sınıfa girerek anketle ilgili açıklamalar yapmış ve öğrencilerin anketi doldurmaları esnasındaki sorularını cevaplamıştır.

Araştırmadan elde edilen verilerin analizlerin yapılmasında SPSS paket istatistik programı kullanılmıştır. SPSS yardımıyla frekans dağılımı, aritmetik ortalama, standart sapma, yüzdeler, ki kare analizi yapılmıştır.

$\mathrm{Bu}$ araştırmayla;

- Üniversite öğrencilerinin mobil oyun oynama nedenleri nelerdir?

- Öğrencilerin cinsiyetleri ile mobil oyun oynama durumu arasında bir ilişki var mıdır? gibi birtakım sorulara cevap aranmıştır.

Araştırma ile ilgili olarak kurulan hipotezde; üniversite öğrencilerinin cinsiyetleri ile mobil oyun oynayıp oynamama arasındaki ilişkiler test edilmiştir. Hipotezin çözümünde Ki-Kare testi uygulanmıştır.

H0: Cinsiyet ile mobil oyun oynama arasında istatistiksel olarak önemli bir ilişki yoktur. 


\section{BULGULAR VE YORUMLAR}

$\mathrm{Bu}$ araştırmada üniversite öğrencilerinin mobil oyun profili ve oynama alışkanlıkları analiz edilmiştir. Bulgular, frekans dağılımlarını ortaya koyan tablolar şeklinde ifade edilmiştir. İlk kategoriye ait frekans ve yüzde dağılımları Tablo 1'de verilmiştir. Burada demografik özelliklere ilişkin tablolar ayrıntılı bir şekilde yorumlanmayıp, göze çarpan bazı rakamlara yer verilmeye çalışılmıştır. $\mathrm{Bu}$ sonuçlara göre elde edilen bulgular şu şekildedir:

Tablo 1. Cinsiyet Değişkenlerine Göre Dağı̆lımı.

\begin{tabular}{ll}
\hline Cinsiyet & Oran \\
\hline Kız & $\% 69,2$ \\
Erkek & $\% 30,8$ \\
\hline
\end{tabular}

Araştırmaya katılanların \%69,2'sini kız \%30,8'ini de erkek öğrenciler oluşturmuştur. Kızların erkeklerden fazla olma sebebi Güzel Sanatlar ve Tasarım Fakültesi’nde erkeklerin sayıca azınlıkta olmasıdır.

Tablo 2. Ne Zamandan Beri Telefona Sahip Oldukları.

\begin{tabular}{ll}
\hline Zaman & Oran \\
\hline $1-2$ y1l & $\% 3,6$ \\
$2-4$ y1l & $\% 0$ \\
$4-6$ y1l & $\% 32,1$ \\
6 y1l ve üzeri & $\% 64,3$ \\
\hline
\end{tabular}

Yukarıdaki tabloya bakıldığında araştırmaya katılanların \%64,ü 6 ve yıl ve üzeri zamandan beri bir cep telefonuna sahiptir. Bunu ikinci sırada \%32,1 ile 4-6 yıl arası cep telefonuna sahiplik oranı izlemektedir.

Tablo 3. Ne Zamandan Beri Akıllı Cihaza Sahip Oldukları.

\begin{tabular}{ll}
\hline Zaman & Oran \\
\hline 2 yildan az & $\% 7,3$ \\
2-4 y1l & $\% 32,7$ \\
\hline
\end{tabular}




\begin{tabular}{ll}
\hline 4 yıldan fazla & $\% 57,5$ \\
Kullanmiyorum & $\% 0,9$ \\
Cevapsiz & $\% 1,6$ \\
\hline
\end{tabular}

Araştırmaya katılanların ne zamandan beri akıllı cihaza sahip olduklarına bakıldığında öğrencilerin \%57,5’i 4 yıldan fazla bir süredir akıllı cihaz kullanmaktadırlar. Bunu takip eden en yakın oran ise \%32,7 ile 2-4 y1l arasidir.

Öğrencilere mobil cihazlarını hangi amaçlar için kullandıkları sorulduğunda, katılımcıların \%69,2'si internet ve sosyal medya kullanımı yanıtını vermiş ve bu yanıtı \%27,6 ile iletişim, \%2,4 ile oyun, \%0,8 ile de mesajlaşma takip etmektedir.

Mobil oyun oynama tercihleri ile cinsiyet arasında Ki-Kare testi yapılmış olup, bu test sayesinde bir ilişki olup olmadığı tespit edilmeye çalışılmıştır. Aşağıdaki tablolarda (Tablo 4) Ki-Kare analizleri yer almaktadır.

Tablo 4. Mobil Oyun Oynama Tercihleri ile Cinsiyet Arasındaki İlişsi.

\begin{tabular}{lllll}
\hline Cinsiyet & $\begin{array}{l}\text { Browser } \\
\text { Oyunlar1 }\end{array}$ & $\begin{array}{l}\text { Online } \\
\text { Oyunlar }\end{array}$ & $\begin{array}{l}\text { Offline } \\
\text { Oyunlar }\end{array}$ & Diğer \\
\hline $\mathrm{K} 1 \mathrm{z}$ & $\% 1,1$ & $\% 25,1$ & $\% 10$ & $\% 9,2$ \\
Erkek & $\% 1,5$ & $\% 28,2$ & $\% 11$ & $\% 12$ \\
\hline \multicolumn{5}{c}{$[\chi 2 \mathrm{y}=1,132, \mathrm{sd}=1, \mathrm{P}=0,226]$}
\end{tabular}

Tablo 4'e bakıldığında, mobil cihazlarında online oyunları oynayan öğrencilerin oranı $\% 53,3$ ile en fazladır. Bu tercihi $\% 21,2$ oranla diğer, $\% 21$ oranla offline oyunlar ve \%2,6 ile browser oyunları izlemektedir.

Tablo 4'te görüldüğü üzere, araştırmanın yapıldığı öğrencilerin cinsiyetleri ile mobil oyun tercihleri arasında bir ilişki bulunamamıştır. Günümüzde cinsiyet ayırımı yapılmaksızın pek çok genç kız-erkek mobil oyun oynamaktadır.

Tablo 5. Mobil Cihazlarda Aylık Kullanılan İnternet Miktarı.

\begin{tabular}{ll}
\hline Miktar & Oran \\
\hline 1 GB & $\% 3,2$ \\
$2-4$ GB & $\% 49,8$ \\
4 GB ve üzeri & $\% 47$ \\
\hline
\end{tabular}




İnternet Kullanmiyorum $\quad \% 0$

Tablo 5 incelendiğinde, $\% 49,8$ oranla öğrencilerin neredeyse yarıs1 mobil cihazlarında aylık $4 \mathrm{~GB}$ ve üzeri internet kullandığı anlaşılmaktadır. Buna en yakın oran ise \%47 ile aylık 2-4 GB seçeneğidir.

Tablo 6. Mobil Cihazlarda Oynanan Oyun Türleri.

\begin{tabular}{ll}
\hline Tür & Oran \\
\hline Aksiyon/Macera & $\% 35,7$ \\
Savaş/Dövüş & $\% 15,7$ \\
Yarış/Spor & $\% 21,2$ \\
Eğitici Oyunlar & $\% 16,1$ \\
Cevapsiz & $\% 11,3$ \\
\hline
\end{tabular}

Tablo 6'ya göre, araştırmaya katılan üniversite öğrencilerinin mobil cihazlarında \%35,7 oranla en fazla aksiyon/macera oyunlarını tercih ettikleri görülmektedir. Bunu sonucu \%21,2 oranla yarış/spor, \%16,1 oranla eğitici oyunlar ve \%15,7 oranla da savaş/dövüş oyunları takip etmektedir. Soruyu cevapsız bırakanların oranı ise $\% 11,3$ 'tür.

Araştırmadaki katılımcıların mobil oyun oynama amaçlarına verdikleri cevaplara bakıldığında, \%50,8'i zevk/eğlence için, \%31,3’ü stres atmak için, \%7,3'ü eğitim amaçlı oynadığı anlaşılmaktadır. Soruya yanıt vermeyenlerin oranı ise \%10,6'dır. Bu sonuçlara göre, öğrencilerin yarısının mobil oyunları zevk/eğlence için oynadıkları gözlenmektedir.

Tablo 7. Mobil Oyun Oynama Günlük Zaman Aralıkları

\begin{tabular}{ll}
\hline Zaman Aralıkları & Oran \\
\hline $10.00-12.00$ & $\% 4,2$ \\
$14.00-18.00$ & $\% 8,9$ \\
$18.00-22.00$ & $\% 35,3$ \\
$22.00-02.00$ & $\% 37,7$ \\
Cevapsiz & $\% 13,9$ \\
\hline
\end{tabular}

Tablo 7'deki sonuçlara göre öğrencilerin \%37,7 oranla en fazla 22.00 02.00 saatlerinde oyun oynadıkları görülmektedir. İkinci sırada ise \%35,3 oranla $18.00-22.00$ saatlerinde mobil oyun oynamaktadırlar. 
Tablo 8. Öğrencilerin Mobil Oyunları Nerede- Ne Şekilde Oynadıkları

\begin{tabular}{ll}
\hline Nerede-Ne Şekilde & Oran \\
\hline Okulda & $\% 0,8$ \\
Beklerken & $\% 14,5$ \\
Boş zamanlarda & $\% 65,7$ \\
Seyahat ederken & $\% 6,7$ \\
Cevapsiz & $\% 12,3$ \\
\hline
\end{tabular}

Tablo 8 incelendiğinde katılımcıların \%65,7'si gibi büyük bir çoğunluğunun boş zamanlarını oyun oynayarak geçirdiği anlaşılmaktadır. Bu sonucu \%14,5 beklerken, \%6,7'si seyahat ederken, $\% 0,8$ 'i ise okulda oyun oynadıkları takip etmektedir.

Araştırmaya katılan öğrencilere yeni mobil oyunları nereden haberdar olduğu sorulduğunda öğrencilerin \%29,2 oranla yaklaşık üçte biri arkadaş yanıtı vermiştir. Bu yanıtı \%28,4'ü internet, \%22,2'si sosyal medya, \%7,9'u diğer cevabı izlemektedir. \%12,3’ü ise soruyu cevapsız bırakmıştır.

Tablo 9. En Çok İndirilenler Listesinde Yer Alan Mobil Oyunlardan Hangisini Tercih Ettikleri

\begin{tabular}{ll}
\hline Oyun Ad1 & Oran \\
\hline Subway Surfers & $\% 11,3$ \\
Toy Plast & $\% 2,6$ \\
Candy Crush Saga & $\% 20,5$ \\
Hungry Shark Evolution & $\% 0$ \\
Çanak Okey & $\% 5,3$ \\
Dr. Driving & $\% 0,8$ \\
8 Ball Poll & $\% 0$ \\
Dream League Soccer & $\% 5,4$ \\
Hill Climbing Racing & $\% 3,6$ \\
Asphalt 8 & $\% 7,9$ \\
Mobile Legend & $\% 2,6$ \\
Hiçbiri & $\% 29,5$ \\
Cevapsiz & $\% 10,5$ \\
\hline
\end{tabular}

Katılımcıların yaklaşık üçte biri Tablo 9'de yer alan mobil oyunların en çok indirilenler listesindeki oyunlardan hiçbirini oynamadığını belirtmiştir. Bu seçeneği \%20,5 ile Candy Crush ve diğer seçenekler takip etmektedir.

Tablo 10. Kaç Yıldır Mobil Oyun Oynadıkları

\begin{tabular}{ll}
\hline Süre & Oran \\
\hline
\end{tabular}




\begin{tabular}{ll}
\hline 1 yildan az & $\% 32,7$ \\
$1-3$ y1l & $\% 24,8$ \\
$3-5$ y1l & $\% 17,3$ \\
5 yildan fazla & $\% 12,1$ \\
Cevapsiz & $\% 13,1$ \\
\hline
\end{tabular}

Tablo 10'a bakıldığında araştırmadaki katılımcıların \%32,7 ile çoğunluğunun 1 yıldan az mobil oyun oynadığı gözlenmektedir. İkinci sırada 1-3 yıl ve üçüncü sırada 3-5 yıl seçenekleri gelmektedir.

Tablo 11. Ortalama Günlük Mobil Oyun Oynama Süresi.

\begin{tabular}{ll}
\hline Süre & Oran \\
\hline $0-1$ saat & $\% 50,6$ \\
$1-3$ saat & $\% 26,2$ \\
$3-6$ saat & $\% 7,5$ \\
6 saat ve üzeri & $\% 2,6$ \\
Cevapsiz & $\% 13,1$ \\
\hline
\end{tabular}

Tablo 11'a göre öğrencilerin \%50,6 oranla yarısından fazlasının günde 0-1 saat arası mobil oyun oynadığı görülmektedir. Bunu takip eden en yakın oran ise \%26 ile 1-3 saat seçeneğidir.

Tablo 12. Mobil Oyunların Yabancı Dil Öğrenimine Katkısı.

\begin{tabular}{ll}
\hline Yanit & Oran \\
\hline Evet & $\% 30,2$ \\
Hayır & $\% 16,3$ \\
Kismen & $\% 45,6$ \\
Cevapsiz & $\% 7,9$ \\
\hline
\end{tabular}

Tablo 12'de görüldüğü üzere katılımcıların \%45,6'sı mobil oyunların yabancı dil öğrenimine kısmen katk1 sağladığ oranla evet, \%16,3 oranla ise hayır seçeneği takip etmektedir.

Tablo 13. Mobil Oyunların Yaratıcıllı̆a Etkisi

\begin{tabular}{ll}
\hline Yanit & Oran \\
\hline Evet & $\% 66,7$ \\
Hayır & $\% 33,3$ \\
\hline
\end{tabular}

Tablo 13'deki sonuçlara göre $\% 66,7$ oranla katılımcıların üçte ikisi evet seçeneğini işaretlemiştir. Katılımcılara verdikleri cevabın nedeni 
sorulduğunda evet seçeneğini işaretleyenlerin ağırlıklı olarak verdikleri cevaplar şunlardır: hayal gücünü arttırması, görsel olarak dikkat çekmesi ve içerisinde farklı görselleri barındırması, farklı tasarımlar ve fikirler sunması, zihni ve görsel zekâyı geliştirmesi, gözleme dayalı etkisi olup yaratıı bakış açısı sağlaması.

Yine Tablo 13'deki hayır seçeneğini işaretleyenlerin nedenine verdikleri cevap ise genel olarak mobil uygulamaların tam anlamıla yaratıcılığa etkisini düşünmedikleri yönünde olmuştur.

Araştırmadaki katılımcılara mobil oyunların olumlu ve olumsuz yanlanı açık uçlu olarak sorulduğunda, katılımcıların en çok verdiği cevaplar ana başlıklar halinde gruplanmış ve bu ana başlıklara göre oranlanmıştır. Oynadıkları mobil oyunlara olumlu yanına yanıt verenlerin \%23,1'i stres atmaya yardımcı olduğunu, \%8,8'i boş zaman etkinliği olduğunu, \% 7,7'si eğlenceli olduğunu, \%6,6'si farklı şeyler öğrenebildiklerini ve zeka geliştirdiğini, $\% 5,5$ 'i düşünce gücünü geliştirdiğini, $\% 4,4$ 'ü bilgi oyunlarının genel kültür anlamında katkı sağladığını, \%3,2'si dikkat seviyesini arttırdığını belirtmiştir. Katılımcıların \%6,6'sı ise çeşitli yanıtlar vermiştir. Oynadıkları mobil oyunlara olumsuz yanina yanit verenlerin ise \% 37,3'ü zaman kaybı olduğunu ve vaktin boşa geçtiğini, \%17,6'sı bağımlılık yaptığını, \%3,3'ü şarjlarının çabuk bitmesine neden olduğunu, \%2,2'si kendilerini sinirlendirdiğini belirtmiştir. Öğrencilerin \% $\%, 5$ 'i ise çeşitli yanıtlar vermiştir.

Araştırmaya katılanların \%34,1 oranla büyük bir çoğunluğu soruyu yanıtsız bırakmıştır. Bunun nedeni olarak katılımcıların açık uçlu sorulara yanıt vermede çekingen davrandıkları düşünülmektedir.

\section{TARTIŞMA, SONUÇ VE ÖNERILER}

$\mathrm{Bu}$ araştırma üniversite öğrencilerinin mobil oyun oynama alışkanlıklarını ve tercihlerini belirlemek amacıyla yapılmış bir çalışmadır. Teknolojinin günden güne gelişmesiyle birlikte bilgisayar ve türevleri yerini ulaşılabilirliği ve taşınabilirliği kolay olan mobil cihazlara bırakmış ve bu cihazlar günlük yaşamın vazgeçilmez bir parçası haline gelmiştir. İnsanlar bu cihazları gün içerisinde iletişim, internet, sosyal medya ve özellikle oyun gibi 
birçok sebepten ötürü kullanmaktadır. Bu çalışmada oyun baz alınarak bunların nedenleri ve kişilerin tercihlerinin ne yönde olduğu araştırılmış ve birtakım sonuçlara ulaşılmıştır.

Araştırmaya katılanların büyük çoğunluğu uzun süredir akıllı telefon kullandıklarını belirtmişler. $\mathrm{Bu}$ durumda öğrencilerin çok küçük yaştan itibaren teknolojik cihazlarla tanıştıkları ve aktif olarak kullandıkları görülmektedir. Mobil cihazlarını internet ve sosyal medya için kullanmaktadırlar.

Buna göre eğitici oyunları oynayanların yarısından azı bu oyunları sadece eğitim amaçlı oynamaktadır. Öğrencilerinin yarısından fazlasının boş zaman değerlendirme aktivitesi olarak oyun oynadığı görülmektedir. Öğrencilerin ödev, iletişim ve eğlenceyi firsat olarak görmesinin nedeni, alan yazındaki çalışmalarda belirlendiği üzere oyun oynama, bilgi arama ve haberleşme amaçlı kullanımlarının ön plana çıkması olabilir (Sakarya, Tercan \& Çoklar, 2012; Ersoy \& Türkkan, 2009).

$\mathrm{Bu}$ çalışmada yapılan Ki Kare testinde ilişki aranmaya çalışılmış; Mobil oyun oynama tercihleri ile cinsiyet arasında anlamlı bir ilişki bulunamamıştır.

Teknolojinin gelişmesiyle artık internetin ve teknolojik cihazların bulunduğu her ortam dünyaya açılmış, bu sayede kişilerin kendilerini geliştirmeleri ve dil öğrenmeleri kolaylaşmıştır. Özellikle çağın en büyük vakit geçirme aracı olan oyunlar vasıtasıyla dünyanın her yeriyle etkileşim haline geçilmiş ve farklı yerlerdeki insanlarla oyun oynama firsatı sunulmuştur. $\mathrm{Bu}$ etkileşimler ile dil öğrenimi kolaylaşmıştır. Elde edilen bu bulguya neden olarak, günümüzde teknolojinin gün geçtikçe ucuzlamasıyla birlikte teknolojiye ulaşılabilirlik düzeyinin artması ve hemen hemen her evde bilgisayar, tablet ve akıllı telefon gibi teknolojik araç gereçlerin bir ya da daha fazlasının yer alması gösterilebilir.

Ayrıca mobil oyunların olumlu ve olumsuz yanları araştırıldığında soruya yanıt verenlerin çoğunluğu olumlu olarak stres atmaya yardımcı olduğunu, olumsuz olarak da zamanlarının boşa geçtiği yanıtını vermişlerdir. Öğrencilerin zamanlarını oyunlarla olumlu bir şekilde 
değerlendiremediklerini bildikleri halde yine de oyunlar oynamaktan vazgeçmemeleri bir çelişki oluşturmaktadır.

Sonuç olarak araştırmaya katılan öğrencilerin firsat buldukça internet, sosyal medya ve mobil oyunlar ile zamanlarını olumsuz bir şekilde geçirdiği görülmektedir. İnternet, sosyal medya ve oyunlar her ne kadar çağın iletişim aracı olarak görülse de toplumda insanlar arasında gerçek anlamda bir iletişim aracı olmaktan uzaktır. Boş zamanlarını oyun oynayarak geçiren kişiler ise dijital oyun dünyasındaki gelişme ve yenilikler ile kendilerini sürekli içine çeken bir girdap içerisinde bulmalarına ve zaman içerisinde toplumdan kendilerini soyutlamalarına neden olmaktadır.

Araştırmada elde edilen bulgulardan hareketle şu önerilerde bulunmakta mümkündür:

- Araştırma, farklı yaş gruplarında ve belli aralıklarla uygulanıp sonuçlar değerlendirilebilir.

- Öğrencilerin, teknolojinin farklı işlevlerini keşfetmesini sağlayacak etkinlikler yapılabilir, öğrenme ortamları ve sosyal hayatlarında desteklenebilir.

\section{KAYNAKLAR}

Altuntaş, B. \& Karaarslan, M. H. (2017). Kullanıcıların Mobil Oyun Tercihinde Etkili Olan Faktör Düzeylerinin Öneminin Belirlenmesi. Uluslararası İktisadi ve İdari İncelemeler Dergisi -IJEAS, 2017 (19):277-298 ISSN 13079832.

Aydoğdu Karaaslan, İ. (2015). Dijital Oyunlar Ve Dijital Şiddet Farkındalığı: Ebeveyn Ve Çocuklar Üzerinde Yapılan Karşılaştırmalı Bir Analiz. Uluslararası Sosyal Araştırmalar Dergisi, Cilt: 8 Sayı: 36.

Aykutlu, I. \& Şen, A. İ. (2004). Oyun Tabanlı Hazırlanmış Ders Planları ile Fizik Öğretimi. XII. Eğitim Bilimleri Kongresi Bildiriler Kitabı. 3, s. 1993-2003. Ankara: Gazi Üniversitesi.

Bal, E. (2013). Teknoloji Çağında Cep Telefonu Kullanım Alışkanlıkları ve Motivasyonlar: Selçuk Üniversitesi Ögrencileri Üzerine Bir İnceleme. Konya: Yayınlanmamış Doktora Tezi.Selçuk Üniversitesi Sosyal Bilim Enstitüsü.

Bedir Erişti, S. (2016). Yeni Medya ve Görsel İletişim Tasarımı. Ankara: Pegem Akademi.

Binark, M., \& Bayraktutan Sütçü, G. (2008). Kültür Endüstrisi Ürünü Olarak Dijital Oyun. İstanbul: Kalkedon Yayınları. 
Çelik, S., \& Akadal, E. (2014). Mobil Ticaret Uygulamaları Arayüzleri Üzerine Bir Çalışma. XIX Türkiye'de Internet Konferansı, (s. 66). İzmir.

Ersoy, A., \& Türkkan, B. (2009). İlköğretim öğrencilerinin resimlerinde internet alg1s1. Illköğretim Online, 8(1).

Frasca, G. (2001). Rethinking Agency and Immersion: videogames as a means of consciousness-raising. SIGGRAPH 2001.

Karahisar, T. (2013, Kasım 21-23). Türkiye'de Dijital Oyun Sektörünün Durumu. Sakarya Üniversitesi Uluslararası Sanat Tasarım ve Manipülasyon Sempozyumu, s. 107-113.

Kaya, A. B. (2013). Çevrimiçi Oyun Bă̆ımlılı̆̆ı Ölçeğinin Geliştirilmesi: Geçerlik ve Güvenirlik Çalışması. Tokat: Yayınlanmamış Yüksek Lisans Tezi. Gaziosmanpaşa Üniversitesi Eğitim Bilimleri Enstitüsü.

Koçyiğit, S., \& Başara Baydilek, N. (2015). Okul Öncesi Dönem Çocuklarının Oyun Algılarının İncelenmesi. YYÜ Ĕ̈itim Fakültesi Dergisi. Cilt:XII, Sayı:I,1-26 ISSN:1305-2020.

Küçükali, A. (2015). Çocukların Oyun Oynama Hakkı Ve Değişsen Oyun Kültürü. Erzincan Üniversitesi Sosyal Bilimler Enstitüsü Dergisi. (ERZSOSDE) VIII$\mathrm{I}: 1-14$.

Özkoçak, Y. (2016). Türkiye'de Akıllı Telefon Kullanıcılarının Oyalanma Amaçlı Tercih Ettikleri Mobil Uygulamalar. Global Media Journal, 6(12), s. 106130.

Sakarya, S., Tercan, İ., \& Çoklar, A. N. (2012). İlköğretim öğrencilerinin interneti ve arama motorlarını kullanım durumları. e-Journal of New World Sciences Academy, 7(1), 348-354.

Pala, F. K., \& Erdem, M. (2011, Haziran). Dijital Oyun Tercihi ve Oyun Tercih Nedeni ile Cinsiyet, Sınıf Düzeyi ve Öğrenme Stili Arasındaki İlişkiler Üzerine Bir Çalışma. Ahi Evran Üniversitesi Eğitim Fakültesi Dergisi, 12(2), 53-71.

Yalçın Irmak, A., \& Erdoğan, S. (2016). Ergen ve Genç Yetişkinlerde Dijital Oyun Bağımlılığı: Güncel Bir Bakış. Türk Psikiyatri Dergisi, 27(2), 128-137. 